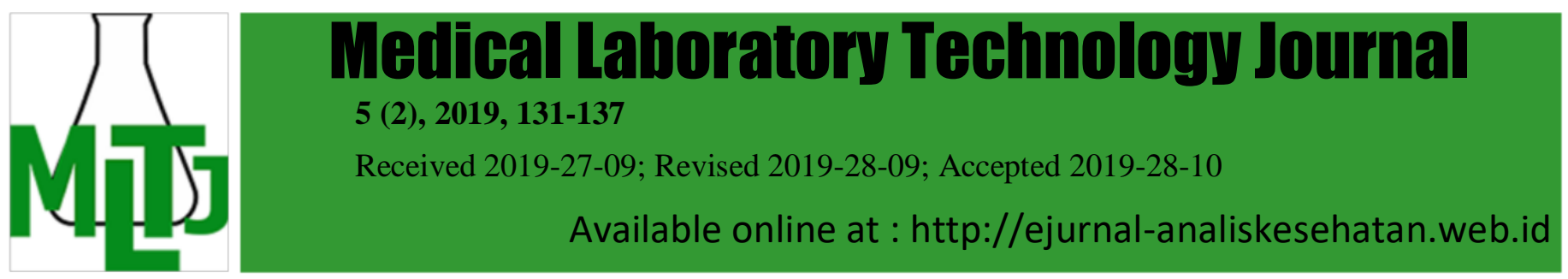

\title{
Analysis between Platelet Count and Blood Groups in Apheresis Platelet Donors with Demographic Features
}

\author{
${ }^{*}$ Canan Eren ${ }^{1,}$ Serpil Cecen ${ }^{2}$ \\ ${ }^{1}$ Marmara University Pendik Training and Research Hospital Medical Microbiology \\ and Blood Bank Department. ${ }^{2}$ Marmara University Pendik Training and \\ Research Hospital Sport Physiology Department. \\ *E-mail: cananeren21@gmail.com \\ DOI: $10.31964 / \mathrm{mltj} . v \%$ vi\%i.250
}

\begin{abstract}
Platelet transfusion is used to prevent bleeding in patients with thrombocytopenia or platelet dysfunction. Purpose of investigating demographic characteristics of eligible volunteers as platelet donors and of demonstrating the association of platelet counts with blood groups as well as other factors. We used data of individuals who referred to a blood center in our hospital. Age, body weight, body mass index (BMI), and gender were determined, and than hemogram values such as leukocyte, hemoglobin, hematocrit, and platelet and ABO blood types of those individuals were identified. A statistically significant difference determined for height, body weight, and BMI in both genders. Although BMI was lower in the group of platelet count $\leq 250$, it was higher in a group of platelet count $>250$. Furthermore, platelet count was more moderate in blood group $\mathrm{O}$ Rh-positive but, no significant difference was group $\mathrm{O}$ Rh-negative. Platelet count was higher in other Rh-positive blood groups than Rh negatives. BMI is vital in apheresis donors, and individuals with higher BMI values may prefer in case of double dose or more apheresis need. The determination of platelet counts in $\mathrm{Rh}$ positives is more elevated than $\mathrm{Rh}$ negatives.
\end{abstract}

Keywords: donor; platelet; apheresis; blood groups

\section{INTRODUCTION}

Blood and blood components still save lives when they are used timely inaccurate indications (Doğu et al., 2015 ). Since the blood has different parts; apheresis is called the procedure where the blood of the patient or donor separated into one or more components by circulating the donor blood into a unique medical device and returning to the donor. Within this context, there are three apheresis procedures, including donor apheresis, therapeutic apheresis, and root cell apheresis (Szczepiorkowski et al., 2010).

Donor plateletpheresis is an apheresis procedure that a cell extraction device removes the platelets of the volunteer donor blood, and platelets are collected while the remaining blood is returned to the donor (Szczepiorkowski et al., 2010). The platelets obtained through plateletpheresis have some advantages in terms of quality and purity as well as prevention of the exposure to multiple donors for certain patients groups such as the lower risk of transfusion-borne infection and lower alloimmunization risk etc. The only source for blood and blood products is still human today, and to find sufficient volunteers for platelet donation, which gradually increases becomes difficult (Pitman et al., 2015 and Woodall et al., 2014 and Yilmaz et al., 2007). 
Platelet transfusion is used to prevent bleeding in patients with thrombocytopenia or platelet dysfunction and to stop any active bleeding (Yin et al.,2013). Compatible blood group platelets should use as much as possible. Platelet concentrates are prepared from complete blood or as plateletpheresis through donor apheresis procedure. One unit of platelets obtained by apheresis is equivalent to random platelets obtained from 3 to 13 units of whole blood (WHO 2012 and Badami et al., 2012).

The actual objective of blood donation is to provide secured blood to the patient. However, the protection of the donor is essential. Donor investigation forms, therefore, created. The donors filled the way and required hematological and serological tests conducted if they are found eligible. After the stages, as mentioned above, the donor is accepted or rejected (Doğu et al., 2015).

The present study aimed to investigate the demographic characteristics of eligible volunteers as platelet donors through apheresis and to review the association of platelet counts with blood groups as well as factors. We also wanted to reveal the relationship between platelet count and blood group, unlike other studies.

\section{MATERIALS AND METHOD}

Data of 2,198 individuals who referred to Blood Centre of Pendik Training and Research Hospital within Marmara University and accepted as donors between 2017 and 2018 were analyzed retrospectively. Demographic characteristics (age, body weight, body mass index (BMI) and gender), hemogram values (leukocyte, hemoglobin, hematocrit, and platelet) and blood types of those individuals were determined. The tests were performed using the BECKMAN COULTER $\mathrm{HmX/Autoloader} \mathrm{system} \mathrm{(Beckman} \mathrm{Coulter,} \mathrm{Inc,} \mathrm{Brea,} \mathrm{CA,} \mathrm{USA).} \mathrm{The} \mathrm{Haemonetics}$ MCS+ system was used to obtain platelet by apheresis. The eligible donors evaluated through some parameters including the body weight, hemoglobin $(\mathrm{Hb})$ level, platelet count, donation frequency; single or double dose platelet suspension obtained according to the need. The present study was approved by the Research Ethics Committee of Faculty of Medicine within Marmara University. Decision code:09.2018.358.

\section{RESULTS AND DISCUSSION}

A statistically significant difference detected between females and males in terms of height, body weight, and BMI; there was not any significant difference for age (Table 1). Furthermore, a considerable difference detected for educational status between females and males. We discovered that males donate blood more than females. The number of males was more in all blood groups (Table 2). BMI of those with a platelet count $\leq 250$ was detected lower than those with a platelet count $>250$ (Table 3). The platelet count was more moderate in blood group $\mathrm{O} \mathrm{Rh}$ positive, whereas no significant difference found in the $\mathrm{O}$ Rh-negative group. Platelet count was found higher in other Rh-positive blood groups; however, the platelet count was detected lower in Rh-negative groups (Table 4). The platelet count was detected more little in individuals with normal BMI and those with grade 1 obesity; platelet count was detected higher in the individuals with grade 2 and morbid obesity (Table 5). 
Table 1. Distribution of anthropometric characteristics according to the gender

\begin{tabular}{cccc}
\hline & Female (Mean \pm SD) & Male (Mean \pm SD) & $\mathrm{p}$ \\
\hline Age & $35.7 \pm 9.265$ & $35.5 \pm 8.90$ & $>0.05$ \\
Height & $165.4 \pm 6.162$ & $175.9 \pm 7.216$ & $<0.05$ \\
Body weight & $67.7 \pm 11.216$ & $82.6 \pm 12.359$ & $<0.05$ \\
BMI & $24.8 \pm 4.112$ & $26.7 \pm 4.001$ & $<0.05$ \\
\hline
\end{tabular}

Table 2. Distribution of demographic characteristics and blood group according to the gender

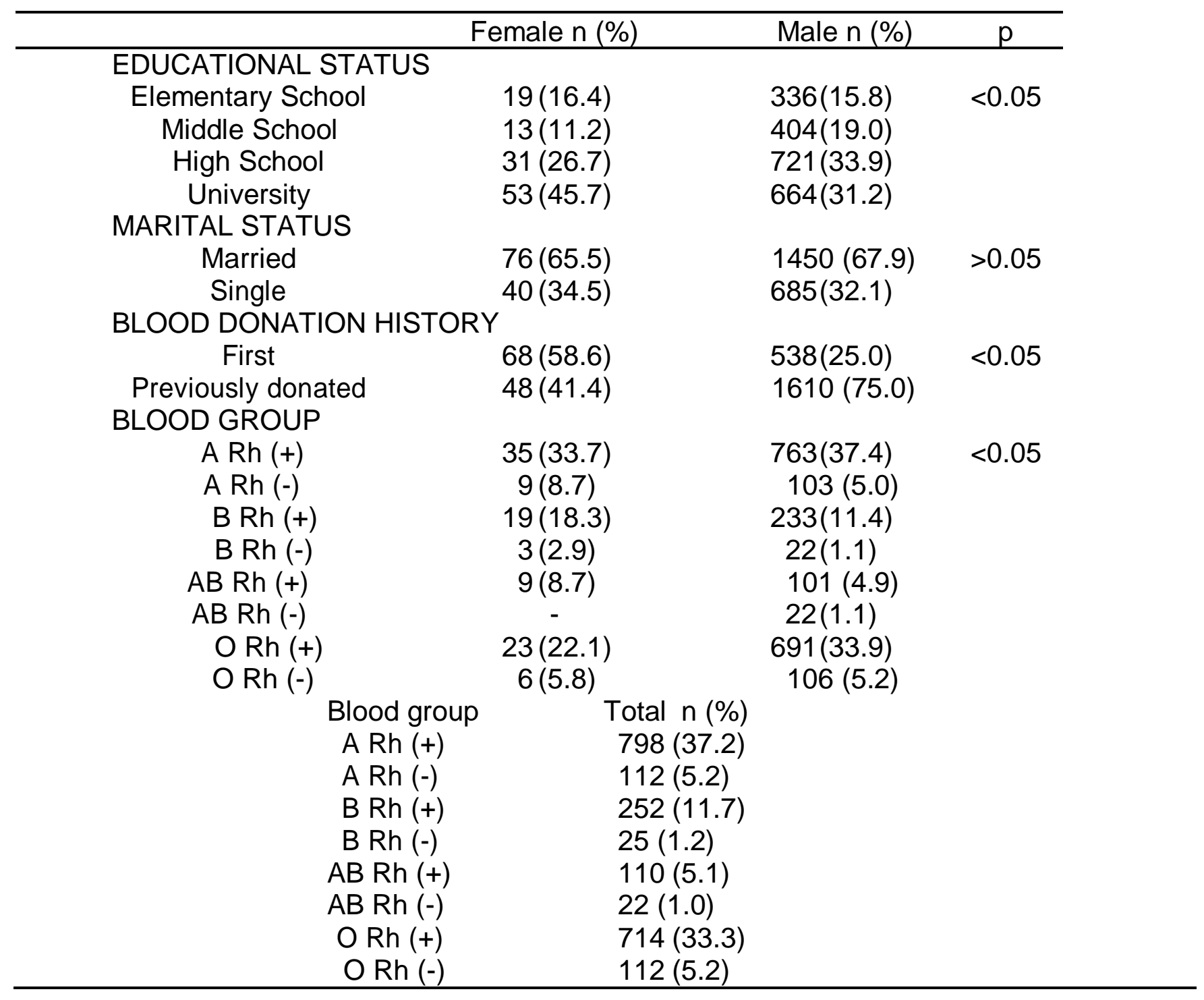


Table 3. Change of the platelet group by body weight and BMI

\begin{tabular}{cccccc}
\hline \multicolumn{2}{c}{ PLT Group } & $\mathrm{n}$ & Mean & $\begin{array}{c}\text { Std. } \\
\text { Deviation }\end{array}$ & $\mathrm{p}$ \\
\hline Body & $\leq 250$ & 1.093 & 81.49 & 12.397 & $>0.05$ \\
weight & $>250$ & 1.106 & 82.13 & 12.990 & \\
BMI & $\leq 250$ & 1.093 & 26.41 & 3.674 & $<0.05$ \\
& $>250$ & 1.105 & 26.85 & 4.335 & \\
\hline
\end{tabular}

Table 4. Distribution of the platelet group by blood groups

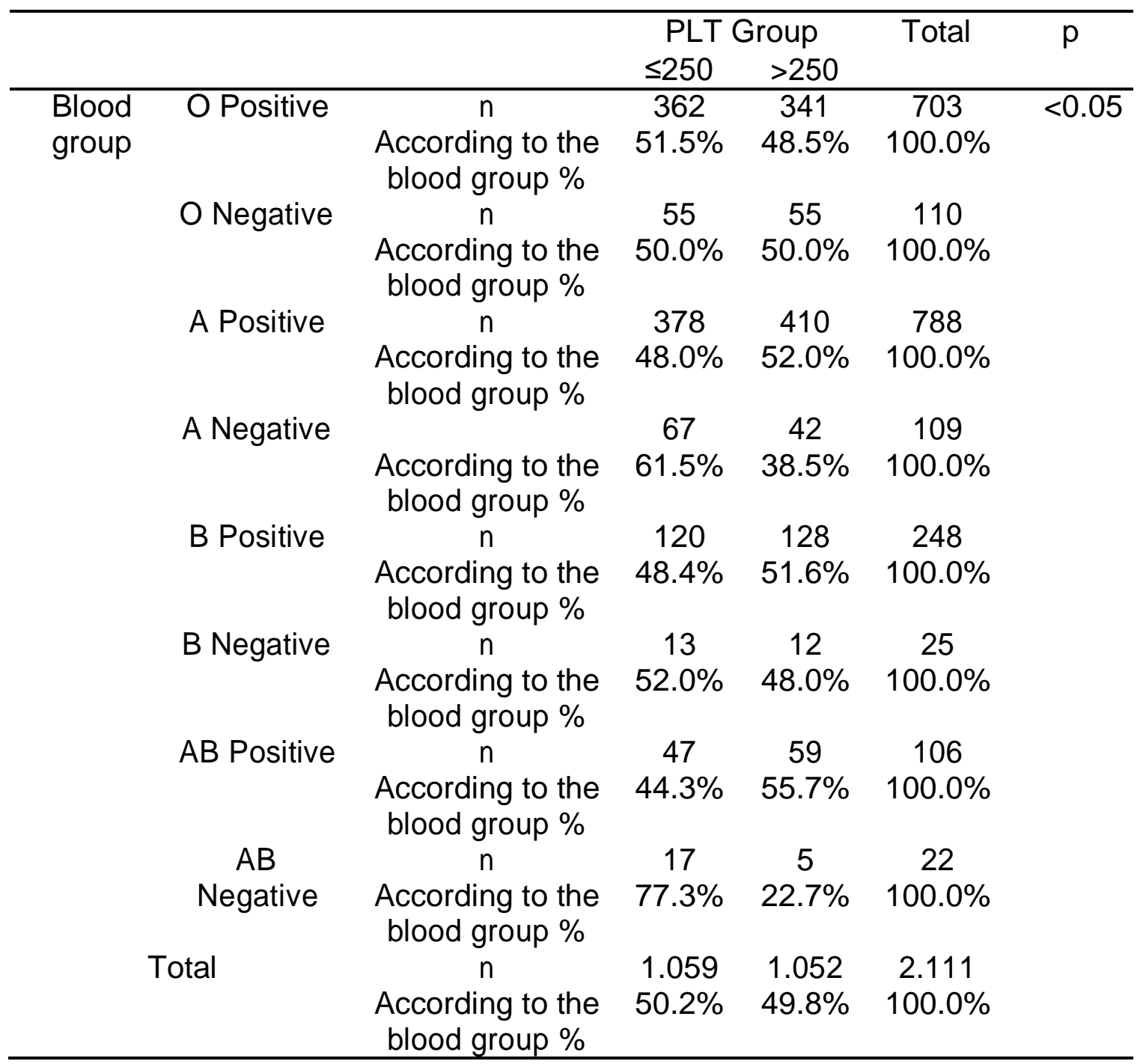


Table 5.The association of the platelet group with BMI

\begin{tabular}{|c|c|c|c|c|c|c|}
\hline & & & PLT & Àroup & Total & $p$ \\
\hline & & & $\leq 250$ & $>250$ & & \\
\hline BMI & Normal & $\mathrm{n}$ & 416 & 372 & 788 & $<0.05$ \\
\hline Group & & $\begin{array}{l}\text { According to } \\
\text { BMI \% }\end{array}$ & $52.8 \%$ & $47.2 \%$ & $100.0 \%$ & \\
\hline & Overweight & $\mathrm{n}$ & 483 & 532 & 1.015 & \\
\hline & & $\begin{array}{c}\text { According to } \\
\text { BMI \% }\end{array}$ & $47.6 \%$ & $52.4 \%$ & $100.0 \%$ & \\
\hline & Grade 1 & $\mathrm{n}$ & 177 & 168 & 345 & \\
\hline & Obesity & $\begin{array}{l}\text { According to } \\
\text { BMI \% }\end{array}$ & $51.3 \%$ & $48.7 \%$ & $100.0 \%$ & \\
\hline & Grade 2 & $\mathrm{n}$ & 12 & 27 & 39 & \\
\hline & Obesity & $\begin{array}{l}\text { According to } \\
\text { BMI \% }\end{array}$ & $30.8 \%$ & $69.2 \%$ & $100.0 \%$ & \\
\hline & Morbid & $\mathrm{n}$ & 5 & 6 & 11 & \\
\hline & Obesity & $\begin{array}{c}\text { According to } \\
\text { BMI \% }\end{array}$ & $45.5 \%$ & $54.5 \%$ & $100.0 \%$ & \\
\hline & Total & $\mathrm{n}$ & 1.093 & 1.105 & 2.198 & \\
\hline & & $\begin{array}{l}\text { According to } \\
\text { BMI } \%\end{array}$ & $49.7 \%$ & $50.3 \%$ & $100.0 \%$ & \\
\hline
\end{tabular}

Chi-square analysis was conducted to detect whether there was an association between blood groups and platelet counts of the individuals. Since $p<0.05$ was obtained as a result of the analysis, it concluded that there was a statistically significant association between the two groups. A review of the table revealed that lower platelet count was higher in negative blood groups with the exclusion of blood group $\mathrm{O}$.

Chi-square analysis was conducted to detect if there is an association between BMI and platelet counts of the individuals. Since $p<0.05$ was identified as a result of the analysis, it concluded that there was a statistically significant association between the two groups. When table 5 above reviewed, lower platelet counts were more in individuals with healthy $\mathrm{BMI}$ and those with grade 1 obesity, whereas higher platelet levels were found more in other groups.

Height, body weight, and $\mathrm{BMI}$ evaluation of females and males revealed that height, body weight, and BMI of males were more; however, we did not detect any difference in terms of age. We discovered that the educational states of the males were higher than females. Furthermore, males donated blood more than females.

Similarly, Dogu et al. reported that males were more for platelet donation by apheresis (Doğu et al., 2015). Moreover, the rate of males was found five-fold more than females in a study conducted in 5 centers in China (Guo et al., 2012). Lower rates of females may consider because females have lower hemogram levels due to menstruation, they have the pregnancy and breastfeeding periods, and they are undereducated. Identically, higher educational level of the males than females is considered to be essential for platelet donation by apheresis (Bani et al., 2010 and Zou et al., 2010).

Blood group distribution of platelet donation by apheresis was A Rh (+) by $37.2 \%, \mathrm{O} h \mathrm{Rh}(+)$ by $33.3 \%$, B Rh (+) by $11.7 \%$, A Rh (-) and O Rh (-) by $5.2 \%$, 
followed by $\mathrm{AB} R \mathrm{Rh}(+)$ by $5.1 \%$, B Rh (+) by $1.2 \%$ and $\mathrm{AB}$ Rh (-) by $1 \%$. Although the distribution of blood group of apheresis donors is substantially similar to blood group distribution rates of our region (Eren, 2019), differences in demands detected due to the needs of hematological-oncological patients as well as a requirement for urgent platelet collection by apheresis during organ transplantation.

Detection of lower BMl values in the individuals with a platelet count $\leq 250$ and higher BMI values in the individuals with a platelet count $>250$, and lower platelet count in those with healthy BMI and grade 1 obesity may suggest the association between platelet count and obesity. A review of the literature demonstrated that an increase of fat tissue in obesity triggers the inflammation (Fantuzzi et al., 2005), and platelets increase as an indicator for (Farhangi et al., 2013) inflammation. Our findings support such information. BMI was shown to be higher in the Rh-positive group in a previous study (Eren and Çeçen 2018), supporting the data that Rh immunization may be associated with BMl and platelet count indirectly.

\section{CONCLUSION}

In consideration of Rh factor in apheresis donors to create a pool for volunteer apheresis donors, detection of platelet count higher in Rh-positive donors than Rhnegative donors would facilitate access of such product which is difficult to obtain by guiding Rh-positive donors initially in case of blood group match when double dose or more apheresis is needed. Similarly, due to the association between BMI and platelet count, BMI monitoring is essential in apheresis donors, and the individuals with higher BMI values may prefer in case of double dose or more requirement for apheresis. It would be useful to make the community more conscious and sensitive to blood donation by raising the awareness of the city to facilitate the access to such product in the centers where plateletpheresis used much would be useful .

\section{REFERENCES}

Badami, K.G., Sesun, M., Basu, A., \& Absolum, N,. (2012). Demographic, laboratory and operational variables that influence short and long term plateletpheresis yields. J Clin Apher, 27, 247-254. doi.org/10.1002/jca.21240.

Bani, M., Giussani, B., (2010). Gender differences in giving blood: a review of the literature. Blood Transfus, 8, 278-87. doi.org/10.2450\%2F2010.0156-09.

Doğu, M.H., Sarı, İ., Ertürk, S., Hacıoğlu, S., \& Keskin, A. (2015). Platelet apheresis donation: Demographic findings, processing and harvest properties. Pam Med J, 8(1), 19-22. Doi:105505/ptd.2015.18480.

Eren, C., Çeçen, S. (2018). An analysis on the association between ABO and Rh blood groups with obesity. Proceedings of National Academy of Sciences, India Section B: Biological Sciences, 89(3), 1095-1100. Doi:10.1007/s40011-0181029-2.

Eren, C. Analysis of distribution of $\mathrm{ABO}$ and Rh blood groups in Istanbul province. (2019). Dicle Med J, 46, 2:241-6. Doi:10.5798/dicletip.539989.

Fantuzzi, G. Adipose tissue, adipokines, and inflammation. Molecular mechanisms in allergy and clinical immunology. (2005). In:Series eds; Shearer, W.T, Rosenwasser L.J, Bochner, B.S. J Allergy Clin Immunol, 115(5), 911-9. doi.org/10.1016/j.jaci.2005.02.023.

Farhangi, M.A., Keshavarz, S.A., Eshraghian, M., Ostadrahimi, A., \& SaboorYaraghi, A.A. (2013). White blood cell count in women: relation to inflammatory biomarkers, haematological profiles, visceral adiposity, and other 
cardiovascular risk factors. J Health Popul Nutr,31, 58-64. Doi:10.3329/jhpn.v31i1.14749.

Guo, N., Wang, J., Ness, P., Yao, F., Dong, X., Bi, X., et al. (2012). Demographics of apheresis platelet donors in five blood centers in China. Transfusion, 52, 560-6. Doi:10.1111/j.1537-2995.2011.03328.x.

Pitman, J.P., Basavaraju, S.V., Shiarishi, R.W, Wilkinson, R., Finckenstein, B.v., Lowrance, D.W., et al. (2015). Namibia's transition from whole-derived pooled platelets to single-donor apheresis platelet collections. Transfusion, 55, 16851692. Doi:10.1111/trf.13049.

Szczepiorkowski, Z.M., Winters, J.L., Bandarenko, N, et al. (2010). Guidelines on the use of therapeutic apheresis in clinical practice-evidence based approach from the Apheresis Applications Committee of the American Society for Apheresis. Apheresis Applications Committee of the American Society for Apheresis. J Clin Apher, 25, 83-177. doi: 10.1002/jca.20240.

Woodall, W.J., Nguyen, V.Q., \& Tran, M.H. (2014). Evaluation of donor factors contributing to plateletpheresis yields among apheresis platelet donors. Journal of Clinical Apheresis, 29, 139-147. Doi:10.1002/jca.21307.

World Health Organization (WHO). Blood donor selection: guidelines on assessing donor suitability for blood donation. Geneva, Switzerland: WHO Press; 2012; Availablefrom:https://www.who.int/bloodsafety/publications/bts_guideline_donor _suitability/en/.

Yilmaz, M., Dikmen, T., Sonmez, M., Akdogan, E., Durmus, A., Omay, S.B., et al. (2007). Change of coagulation parameters after double plateletpheresis. Transfusion and Apheresis Science, 37, 161-163. Doi:10.1016/j.transci.2007.07.004.

Yin, G., Xu, J., Shen, Z., Wang, Y., Zhu, F., \& Lu, H. (2013). The relationship of platelet yield, donor's characteristic and apheresis instruments in China. Transfus Apher Sci, 49, 608-12. doi: 10.1016/j.transci.2013.07.028.

Zou, S., Musavi, F., Notari, E.P., Stramer, S. L., Dodd, R.Y. (2010). Prevalence, incidence, and residual risk of major blood-born infections among apheresis collections to the American Red Cross Blood Services, 2004 through 2008. Transfusion, 50, 1487-94. doi.org/10.1111/j.1537-2995.2010.02621.x 